\title{
Recovering the Space for Indigenous Self-Determination: Multicultural Education in Colonized Hawai' $i$
}

\author{
Jeffrey A. S. Moniz \\ University of Hawai'i at Mānoa \\ U. S. A.
}

In this piece, the author presents key problems with multiculturalism and multicultural education as expressed by those involved in indigenous education

in Hawai'i. The author describes the racialized identities and hierarchies in the island setting and articulates an approach to multicultural education, grounded in multicultural experiences in Hawai'i. This organic approach, which is rooted in the blending of indigenous and settler cultures, addresses the impasse by emphasizing the rights of indigenous people, including the right of selfdetermination.

The Problem with Multicultural Education in Hawai' $i$ Indigenous Arguments Against Multicultural Education Identity and Hierarchies in Hawai'i An Approach to Multicultural Education Organic to Hawai' $i$

Resolution

Notes

References

\section{The Problem with Multicultural Education in Hawai' $i$}

In Hawai'i, Hawaiians are categorized as just another group of immigrants who happened along some 2,000 years before whites and Asians. Words like "indigenous" are never used by scholars or lay people to describe Hawaiians. Nor is the word "settler" used to describe immigrants. As racist as this obviously is, the denial of Native history, culture, and humanity is central to the colonial endeavor. (Trask, 1999, p. 132)

The words of Haunani-Kay Trask, professor of Hawaiian Studies at the University of Hawai'i and indigenous Hawaiian leader, capture a key concern at the crux of a critical issue that has separated indigenous education from multicultural education in Hawai'i. While the two movements share critical perspectives, like critical pedagogy and commitments to social justice, indigenous leaders in Hawai'i, including those involved in indigenous education, have expressed unease and distrust with multiculturalism and the multicultural education movement.

Trask (2002) summed up the issue during the question-and-answer portion of a public lecture that she gave at the University of California, Los Angeles. In response to a question about the progress of multiculturalism, she 
responded emphatically, "Multiculturalism is a gloss." As a multicultural educator at another University of California campus at that time and as a self-professed multiculturalist, I was shocked because I had agreed with everything she had mentioned in her speech up to then. Her comment struck me especially hard because my own theoretical framework of multiculturalism was derived, primarily, from my experience of being born and raised in multicultural Hawai'i, immersed in a multiculture with strong indigenous influences. The dissonance I experienced at that lecture inspired a deeper reevaluation of my personal perspective. As a non-indigenous scholar and former public school teacher of indigenous Hawaiian children, I was challenged to reevaluate my role in what indigenous Hawaiian scholar Julie Kaomea (2005) called "the perpetuation of Hawai'i's hegemonic dynamics" (p. 38). I conducted a reexamination of my notions of multiculturalism and multicultural education, which, at their foundation, originated under hegemonic conditions in colonized Hawai'i.

This multiculture of Hawai'i that I am referring to is intertwined with the discourse that is often used to trumpet Hawai'i's multicultural diversity. Many in the islands, including tour guides, government leaders, everyday people, and well-regarded scholars, have promoted this discourse of multicultural Hawai'i, often without question. It continues to emphasize how Hawai'i is a place where "immigrant groups from all over the world appear to peacefully coexist" (Lind, 1938). This simple, yet powerful, narrative, which is often invoked by Hawaifi's own inhabitants, celebrates the multicultural society of Hawai'i as a "chop suey nation" (DeLima, 1991) or "mixed-plate culture" (Grant, 2000), a blend of all kinds of ethnic contributions.

Diverse cultural contributions from settler sources coalesced with indigenous culture into a common, Local multiculture. This Local multiculture is also reflected in its own creole language, called Pidgin by its native speakers. While a more detailed elaboration of this Pidgin/Local languaculture ${ }^{\underline{1}}$ and its development would undoubtedly be of important historical, cultural, and sociolinguistic value, this particular piece centers on a certain aspect of Hawaili's Local multiculture - its valuing of multiple perspectives. This valuing of multiple perspectives is a key feature of the definition of multicultural education, as defined by the National Association for Multicultural Education (2003). $\stackrel{2}{\text { First, I }}$ present indigenous arguments against multiculturalism and multicultural education. Next, I briefly describe the Hawai'i context, focusing on issues of identity and social hierarchy. Then, I trace the development of Local multiculture in Hawai'i, focusing on multiple perspectives. I employ this multiple perspectives framework organic to Hawai'i to conceptualize the relationship between indigenous education and multicultural education. Finally, I articulate specific key components that should be included in a multicultural education that both emphasizes Native history and culture and promotes indigenous rights. 


\section{Indigenous Arguments against Multicultural Education}

In order to qualify the following statements being attributed to those involved in Hawaiian indigenous education, a word on my methodology is in order. First, keep in mind that the term indigenous, while being a useful construct for understanding the situation of many around the world, remains purposefully undefined. This is consistent with the practices of the United Nations Permanent Forum on Indigenous Issues and the United Nations Working Group on Indigenous Populations, which have been addressing indigenous issues for over 34 years (United Nations, 2004; 2007). It also respects the basic premise of kuleana, as described by indigenous Hawaiian scholar Sam L. No'eau Warner (1999). The kuleana (the "right, responsibility, and authority") to make decisions on things such as policies and definitions related to an indigenous people belongs to the indigenous group, Hawaiians, in this case - not to a nonHawaiian. For the purposes of this paper, I draw from the description of the concept of indigenous as provided by Jose R. Martinez Cobo, the UN Special Rapporteur of the Sub-Commission on Prevention of Discrimination and Protection of Minorities. Cobo furnished the following as part of his working definition:

On an individual basis, an indigenous person is one who belongs to these indigenous populations through self-identification as indigenous (group consciousness) and is recognized and accepted by these populations as one of its members (acceptance by the group). This preserves for these communities the sovereign right and power to decide who belongs to them, without external interference. (United Nations, 2004, p. 2)

Utilizing this definition, the arguments presented here emanate from several sources who have identified themselves as indigenous educators. Their arguments are expressed here as unitary statements, though these are actually conceptual composites collected from various sources. While this method, derived from the composite storytelling method used in Critical Race Theory (Delgado \& Stefancic, 2001), allows for the parsimonious presentation of these points of convergence, it is not my intent to obscure the points where the various indigenous educators diverge. Since a major purpose of this piece is to encapsulate the main arguments against multiculturalism and multicultural education, I deemed the method used as apropos. The following statements in this section reflect general arguments gleaned from various indigenous educators over the past six years. They are also consistent with the positionality of scholarship by indigenous Hawaiian scholars who have been critical of the role of non-Hawaiians who claim to know what is best for Hawaiians (Kaomea, 2003, 2005; Warner, 1999). 


\section{Multiculturalism Is a Gloss}

Multiculturalism is a gloss. The movement provides an opportunity for ego enhancement among those who benefit from the current structural arrangements in our society. Multiculturalism serves as a way for those benefiting from existing, inequitable, power relations somehow to sooth their conscience. By promoting the multicultural banner, emphasizing diversity in particular, they seek to absolve themselves of the collusion, which is often unconscious, that allows for the maintenance of systems of inequity.

Social justice and justice, in general, are often equated with the concepts of equality or equal opportunity, rather than with what is equitable or fair. Colorblindness is valued, occluding the natal rights of indigenous peoples.

By conceding to those who consciously and unconsciously promote the illusion of diversity and social justice, the beneficiaries of the current inequitable arrangement still manage to retain power and wealth. Business proceeds as usual while people buy into the gloss of an egalitarian, multicultural society.

\section{Multicultural Education Provides a Means for Maintaining that Gloss}

One of the colonizers' main tools for the construction and maintenance of an inequitable society is schooling. Schools in Hawai'i play a large role in reproducing inequitable racial and social hierarchies in the islands. Despite a sincere desire to provide an education that claims to be multicultural and the genuine efforts of many educators, most schools continue to reinscribe racist power relationships based on a legacy of institutionalized hierarchy that has its roots in Haole (White) colonialism.

Multicultural education gets a lot of lip service. It is a required course at the University of Hawai'i for those who are learning to become teachers. If multicultural education is effective at analyzing and addressing how schools continue to routinely perpetuate inequalities, then why do our teachers go out to maintain the same schooling that seems to systematically disadvantage indigenous children? These teachers, many of whom are persons of color themselves, are unconsciously recreating an education that helped them to attain some level of success. Remarkably, this education that provided the opportunity for many of those teachers to achieve a middle class existence is the same education that continues to fail indigenous children. While many of Hawai'i's teachers are people of color (See Table 1), they are not indigenous. Note the percentage of teachers from each group, in comparison with the percentage of students. Also, note how the public school teaching force is largely Japanese and Caucasian while the group that makes up the largest percentage of public school students is indigenous Hawaiian. Our public schools can point to multicultural education and to the overall diversity of Hawai'i to distract from a 
reality that exists in education. Children in Hawai'i are not being taught by a teacher workforce that is representative, proportionally, to the ethnic and racial profile of their students, nor the population of their state. Hawaiian children, who make up almost $27 \%$ of the student population in Hawai'i's public schools, are taught by a faculty that is less than $10 \%$ Hawaiian. In the schools, indigenous people are better represented as assistants or custodians than as teachers or administrators. And, they are taught subject matter determined by standards that fail to value indigenous perspectives. If those involved in education in Hawai'i just examined who is better served and who is underserved via their educational practices and curriculum, they would be faced with the reality of a system of failure for many. Since multicultural education is an integral part of the apparatus of schooling, it bears some culpability.

Table 1. Race/Ethnicity of Hawai'i Public School Teachers, Students, and State 2005-06 (in percent)

\begin{tabular}{|l|c|c|c|}
\hline \multicolumn{1}{|c|}{ Race/Ethnicity } & $\begin{array}{c}\text { Public School } \\
\text { Teachers }\end{array}$ & $\begin{array}{c}\text { Public School } \\
\text { Students }\end{array}$ & State Population \\
\hline Japanese & 31.2 & 9.8 & 20.6 \\
\hline Caucasian & 29.9 & 13.6 & 25.4 \\
\hline Hawaiian & 9.9 & 26.9 & 22.0 \\
\hline Filipino & 5.4 & 20.4 & 14.7 \\
\hline Chinese & 4.2 & 3.2 & 5.3 \\
\hline Korean & 0.9 & 1.3 & *A \\
\hline African-American & 0.8 & 2.4 & NA \\
\hline Samoan & 0.4 & 3.5 & NA \\
\hline Hispanic & 0.3 & 3.0 & NA \\
\hline Native American & 0.0 & 0.6 & 12.0 \\
\hline Other & 17.0 & 15.3 & 100.0 \\
\hline Total & 100.0 & 100.0 & N \\
\hline
\end{tabular}

Sources: Hawai'i Department of Health $(2006$, p. 1) and State of Hawai'i Department of Education (2007) (Note: *Cells with an NA, in the category concerning State population, indicate "not applicable" due to the method of data collection by the Hawai'i Health Survey 2005.)

\section{Identity and Hierarchies in Hawai'i}

In the case of Hawai'i, distinctions among people of color and conceptions of the privileged take on a different character than in the rest of the U.S. in general. This is due to the extraordinary mix of peoples who reside there without one group constituting a majority. The following information in this section is 
provided to illuminate the unique circumstances under which the issues discussed here play out. It is also being provided to furnish an indication of the multiplicity that has contributed to the Local multicultural approach that serves as both the lens and a main focus for the remainder of this article. Also, while a more comprehensive depiction of all of the ethnic and racial groups represented in Hawai'i should be in order, due to space limitations for this piece, I purposely limit the discussion to the five largest racial/ethnic groups in Hawai'i.

\section{The Racial and Ethnic Makeup of People in Hawai'i}

\section{Racial and Ethnic Groups}

In Table 2, I provide the most recently published estimates of population conducted by the Hawai'i Department of Health in $2005(2001,2006)$. As a point of reference, I also include a column showing the same kind of health survey data from the year 2000. This allows for direct comparison to data collected for the 2000 US Census (U.S. Census Bureau, 2001).

Table 2. The Five Largest Racial/Ethnic Groups in Hawai'i (in percent of the total population)

\begin{tabular}{|l|c|c|c|c|}
\hline \multicolumn{1}{|c|}{ Race/ } & $\begin{array}{c}2005 \\
\text { Ethnicity }\end{array}$ & $\begin{array}{c}\mathbf{2 0 0 0} \\
\text { Health Survey }\end{array}$ & $\begin{array}{c}\text { US Census } \\
\mathbf{2 0 0 0} \\
\text { Health Survey } \\
\text { (Race Alone or } \\
\text { in Combination } \\
\text { with Other } \\
\text { Races) }\end{array}$ & $\begin{array}{c}\text { US Census } \\
\mathbf{2 0 0 0} \\
\text { (One Race) }\end{array}$ \\
\hline Caucasian/White & 25.4 & 21.1 & 39.3 & 24.3 \\
\hline Hawaiian & 22.0 & 22.1 & 19.8 & 6.6 \\
\hline Japanese & 20.6 & 21.9 & 24.5 & 16.7 \\
\hline Filipino & 14.7 & 15.9 & 22.8 & 14.1 \\
\hline Chinese & 5.3 & 5.8 & 14.1 & 4.7 \\
\hline
\end{tabular}

Sources: Hawai'i Department of Health (2001, p. 1; 2006, p. 1) and U.S. Census Bureau, Census 2000

(2001)

The differences in these estimates are likely due to differences in methodology, particularly in sample size. The decennial census aims to collect data about virtually everyone in the state (approximately 1.2 million), while the Hawai'i Health Survey size is between 1.4 and $1.5 \%$ of the population. Also, changes in the 2000 U.S. Census race/ethnicity categories make racial and 
ethnic data more difficult to analyze. The new option in 2000 to "check more than one" allowed multiracial and multiethnic people to self-select all of the racial descriptors that apply to them. In the two columns, on the right, depicting U.S. Census 2000 data, the first provides an indication of the percentage of all the people in Hawai'i who claim a particular ancestry. The last column shows the percentage of the people in Hawai'i who claim only that particular ancestry and no other. While there are discrepancies between the Health Department and U.S. Census data, these data, from multiple sources, provide evidence of an undeniable claim about Hawai' $i$ - one large group does not numerically dominate the population. Since no one group constitutes a majority, those who would be considered a minority on the U.S. continent enjoy the advantages of being a majority, when considered under the locally used terms of Haole and Local, which I will describe in the next major section after I briefly address the matter of multiraciality and multiethnicity.

\section{Multiplicity}

U.S. Census Bureau data indicate that people of multiple racial and ethnic backgrounds make up a substantial portion of the population in Hawai'i, especially in contrast to the rest of the U.S. As shown in Table 3, the percentage of people in Hawaili who specified more than one race is $21.4 \%$ compared with $2.4 \%$ for the entire U.S. In fact, the percentage of people who claim three races in Hawai'i also exceeds the "two or more" figure for the nation.

Table 3. Multiracial People in Hawai'i (in percent of the total population)

\begin{tabular}{|c|c|c|}
\hline Number of races & $\begin{array}{c}\text { Percent of Hawai' } \mathbf{i} \\
\text { Population }\end{array}$ & $\begin{array}{c}\text { Percent of U.S. } \\
\text { Population }\end{array}$ \\
\hline Two or more races & 21.4 & \multirow{2}{*}{2.4} \\
\hline Two races & 14.5 \\
\hline Three races & 5.9 \\
\hline Four races & 0.9 & \multirow{2}{|}{} \\
\hline Five races & 0.06 \\
\hline Six races & 0.002 \\
\hline
\end{tabular}

Source: U.S. Census 2000 (U.S. Census Bureau, 2001)

These data, showing Hawai'i's large percentage of people with multiple ancestries, in relation to the national percentage, point to a unique situation in Hawai'i. In fact, the states with the next highest percentages, Alaska (8.1\%) and Oklahoma (6.1\%), do not reflect comparable rates of multiraciality (U.S. Census Bureau, 2006). Unlike most of the U.S., Hawaii never had anti-miscegenation laws (Grant \& Ogawa, 1993). The extraordinary situation in Hawai'i embodies 
circumstances that have contributed to attitudes about race and "race-mixing" that substantially differ from the rest of the U.S.

\section{Differences in the Racial Discourse and Racism between Hawai'i and the Rest of the U.S.}

While Whites are the largest single group in Hawai'i, they do not constitute a majority. As such, race relations take on a different timbre in Hawai'i, when compared to the rest of the U.S. in general. Racial discourse in Hawai'i is not as preoccupied with the White/Black or White/People of Color binaries that dominate racial discourse in the rest of the U.S. Instead people in Hawai'i tend to engage in a racial discourse using the labels of Haole (White) versus Local. They are more apt to apply the description "Hawaiian" to people of indigenous ancestry. The term, as it is used locally, is hardly ever used as a designation for Hawai'i residency, in the way that Californian is used for residents of California.

Much of the dominant racial discourse in Hawai'i occurs using the binary of Haoles and Locals. Referring to the five largest racial/ethnic groups indicated in Table 2 in the Hawai'i racial discourse, Caucasians/Whites are Haole, while Hawaiians, Japanese, Filipinos, and Chinese are generally considered Local. While the dichotomy basically resembles the White/People of Color (or White/Non-White) binary employed in racial discourse on the U.S continent, Local also connotes a particular cultural worldview that can transcend race.

\section{Indigenous Presence}

A key characteristic that also distinguishes Hawai'i from the rest of the U.S. is its proportion of persons of indigenous ancestry that make up its population. In Hawai'i, Hawaiians constitute a relatively significant percentage, about $20 \%$. The percentage of Hawai'i's population that has Native Hawaiian ancestry, when compared to other states with high proportions of American Indian and Alaskan Natives, gives it, arguably, the highest state proportion of indigenous people (U.S. Census Bureau, 2007). Alaska is close, with 19.3\% American Indian and Alaska Native alone or in combination, followed by Oklahoma's 12\% and New Mexico's 10.2\% (U.S. Census Bureau, 2007).

These statistics indicate something that is apparent in the islands - the indigenous people are still quite present. While I tout the $20 \%$ figure as being high, it pales in comparison, of course, to the $100 \%$ at the time of the first contact with Europeans in 1778. A dramatic 80\% drop in the indigenous percentage of Hawai'i's population, over a 230 -year span, shows two things. First, it undeniably demonstrates the devastating effects of colonialism on the indigenous people of Hawai'i. Second, it belies a reality that the indigenous people of Hawai'i will certainly remain rooted in their islands. 


\section{Asian Settler Colonialism}

In 2000, both indigenous and postcolonial scholars began advancing a position that, in effect, shifted the discourse around identity in Hawai'i from the racialized Haole/Local discourse to include a new binary - that of Settler/Indigenous. Basically, they argued that there are just two kinds of people in Hawai' $i$ - those who are settlers (or the descendants of settlers) and those who are indigenous (Trask, 2000, Fujikane, 2000). Figure I depicts this binary, with a boundary line separating the two groups which are shown as ellipses. The ellipses and the boundary line are all encircled by another larger ellipse, representing the context, Hawai'i.

Figure 1: Conceptualizing the Settler/Indigenous Binary

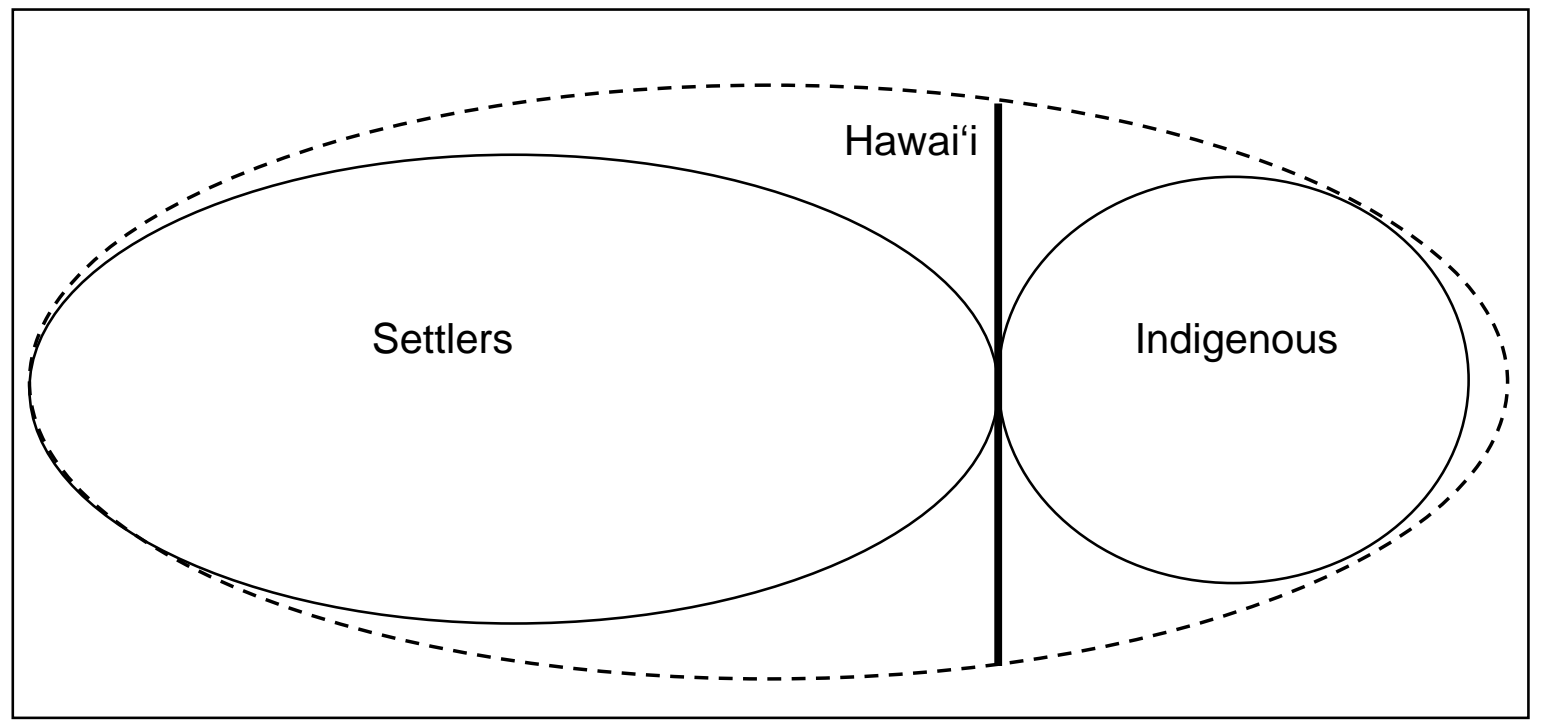

Both Trask (2000) and Fujikane (2000) argue that settlers of color have played a key role in denying indigenous history. They have contributed to the continued dispossession and exploitation of the indigenous people of Hawai'i. Settlers of color have reaped benefits in Hawai'i at the expense of the indigenous people. While Asian settlers have benefited under the protection of the U.S. Civil Rights Act, civil rights ignore indigenous rights. Civil rights fail to address injustices against indigenous peoples, such as genocide, land dispossession, and cultural exploitation. While multicultural Hawai'i became a place where people of color could increasingly attain wealth and power, those people of color tended to be Asian—not indigenous.

In fact, many in Hawai'i consider those of Asian descent, particularly those of Japanese or Chinese ancestry, as occupying a higher place on the social hierarchy than Caucasians in various contexts (Okamura, 1998). This atypical social status is most noticeable in the areas of politics and education. Asians possess a disproportionate amount of power in Hawai'i's educational system (Okamura, 1980). There is a strong perception that the University of Hawai'i and 
the public school system of the state of Hawai'i are largely dominated by those of Asian ancestry. So, while Whites do possess much power in Hawai'i, White privilege does not reign as supremely as on the U.S. continent. In Hawai'i, according to those who assert the Asian settler colonialism discourse, White and Asian settlers reign together.

Still, while there are qualitative differences to the timbre of race relations between Hawai'i and the rest of the U.S., there are similarities. Social hierarchies operate in ways that perpetuate social stratification in areas such as educational attainment, home ownership, wealth, and incarceration rates. Although the terms of the dominant racial discourses differ, they are, for the most part, derived from the same narrative of White supremacy. While the current, dominant racial discourse in the U.S. is conducted in terms of Whites and people of color, Hawai'i's is conducted in terms of Haoles and Locals, which obscures important distinctions among Whites and people of color in Hawai'i.

\section{An Approach to Multicultural Education Organic to Hawai' $i$}

\section{Local Multiculture}

A dichotomy has divided the population in Hawaili since its days of a plantation-driven economy that began ramping up in the mid-1800s. Whites held most of the positions of power as plantation owners, managers, supervisors, financiers, and merchants. Non-Whites did the backbreaking work at meager wages as plantation laborers, service workers, and domestics. The roots of Local identity and culture developed out of this shared class experience. Egalitarian attitudes towards other ethnic groups also grew out of familiarity facilitated by the passage of time and expedited by living and working in close proximity. Most importantly, non-Native and non-White residents took up the prevailing attitude of aloha ${ }^{3}$, or love, from both the authentic Native source and from discourse promoted by powerful Whites who sought to mask their own racial privilege, establish social control, and attract visitors to the islands. Non-Whites embraced the melting pot ideal promoted by the White elite. Non-Whites easily bought into the myth because it was based on an authentic Hawaiian value, aloha, and because the social conditions of the islands were ripe for panethnic alliances among its working class. The Hawaiian value of aloha was the glue that facilitated the formation of alliances that crossed ethnic boundaries (Grant \& Ogawa,1993; Moniz \& Spickard, 2006).

Non-White workers from various ethnic groups forged alliances. Filipino, Japanese, Chinese, Spanish, and Portuguese workers cooperated with each other. Their solidarity prevented the planters from effectively pitting ethnic groups against each other as strikebreakers, which had been the planters' prevailing strategy. In 1920, an interethnic strike resulted in the planters eventually meeting the strikers' demands. The time was marked by a sense of cooperation and unity that transcended ethnic boundaries. 
This panethnic unity further solidified during a series of highly publicized events surrounding the Massie Case of 1931-32. The sensationalized case, which made national headlines, concerned a White woman, the wife of a US naval officer, who was allegedly raped by a group of five young men. Two of the men were Native Hawaiian, two were Japanese, and one was of mixed Native Hawaiian and Chinese ancestry. The rape case ended in a mistrial. Angered by the mistrial, the husband and mother of Thalia Massie, the alleged victim, with the help of two Naval midshipman, took matters into their own hands and lynched Joseph Kahahawai, one of the accused five. The White vigilantes were found guilty of manslaughter. They were sentenced to 10 years of hard labor, only to have their sentence commuted to one day served in the territorial governor's office. The case was an insult to non-Whites, who overwhelmingly identified with the "local boys." Discussions of the Massie Case, whether in print media or on the lips of gossips, are often cited as the first time that the term "Local" was used with any salience (Rosa, 2000; Yamamoto,1979).

The Local panethnic unity further solidified during World War II, when the distinction between non-Whites and the hordes of White military servicemen stationed in the islands became even more apparent. Solidarity manifested itself once again, in the form of the large-scale sugar strikes of 1946. Workers of all of the various ethnic groups drew on their shared experiences of mistreatment by American Whites and combined together in one labor organization - the ClOILWU (Rademaker, 1947). This alliance, nurtured by harmonious race relations reinforced by the promotion of aloha, developed into a common identity. This common identity coalesced over time as a result of social interactions among different ethnic groups at work, school, and church, in the community, in leisure activities, and in the home, most notably through intermarriage (Okamura, 1998).

Various character traits are associated with Local culture. They include being "easygoing, friendly, open, trusting, humble, generous, loyal to family and friends, and indifferent to achieved status distinctions" (Okamura, 1998, p. 268). These are attributes that characterize the positive perceptions of Native Hawaiians and are in opposition to conventional White American values that emphasize "directness, competition, individualism, achievement of status, and the necessity for impersonal, contractual relationships." Jonathan Okamura (1980) describes Local as the common identity of people of Hawaili and their appreciation of the inherent value of the land, peoples, and cultures of the islands.

\section{Multiple Perspectives}

In Hawai'i, Local consciousness is split, "sometimes mimicking and other times resisting colonial narratives" (Chang, 1996, p. 3). Chang's notion of Local consciousness accurately describes the fluid nature of Local identity that is so dependent on context. Sometimes Hawai'i Locals reflect more White American values and sometimes they exhibit more Hawaiian values or the values of their 
non-White, non-Hawaiian, ethnic ancestry. Due to the range of fluidity between and among value systems, "Localness" can be difficult to pin down. That is, unless multiplicity and fluidity are considered as key characteristics of Local identity. These are also important characteristics of the notion of multiple perspectives, a key concept in multicultural education.

The valuing of multiplicity is essential to being Local. Whether it be possessing a multiplicity of racial backgrounds, a syncretic worldview, or a worldview different than the one usually associated with one's racialized identity, multiplicity is an essential attribute of being Local.

The valuing of multiplicity is also a central tenet of multiculturalism and multicultural education. Multiculturalism is a skill that needs to be acquired in order for our children to function and thrive in today's world. If educators are truly interested in contributing to a just and humane society, we need to build a democracy that is inclusive of all groups and often-conflicting worldviews. An approach that is grounded in the experiences of individuals raised in a multiculture and their multicultural, multigenerational families offer that promise. Specifically, this approach entails a model of instruction, positioned in a sort of middle space, which draws from the varied backgrounds of students and develops the skills necessary to view phenomena from multiple points of view.

The other essential characteristic of the multiple-perspectives approach inherent in being Local is the fluidity that accounts for the perception of Locals possessing split consciousnesses that vary depending on context. The performance of one's identity can shift dramatically between situations. The recognition of the contextual nature of identity allows the potential for one's identity to broaden beyond just one dimension.

\section{The Approach from the Local Midaltern}

This Local multicultural perspective is characteristic of the sort of middle space between and around dichotomous categories. Moniz and Spickard (2006) offered the concept of the midaltern, positioned between superaltern and subaltern identities. The superaltern represents the colonizer, the dominant, the oppressor, and settlers, so to speak. The subaltern represents the colonized, the dominated, the oppressed, and, of course, indigenous peoples. The midaltern, in this case the Local midaltern, represents the center between superaltern and subaltern identities.

While theories of middle or third spaces may not be new, the introduction of the midaltern to postcolonial discourse regarding indigenous peoples provides an additional dimension to the discussion. It allows for the conceptualization of a wider range of possibilities. Rather than assigning people into static, essentialized, either/or categories, Local midalternity recognizes the existence and importance of multiplicity. The fluidity of the midaltern, represented by double-headed arrows in Figure 2, allows for the consideration of context and 
worldview in regards to identity. The performance of one's identity can shift dramatically between contexts. Local midalternity provides the conceptual space to consider shifts, depending on the situation. Midalternity's recognition of the contextual nature of identity allows the potential for one's identity to broaden beyond just one dimension.

Figure 2. Conceptualizing the Relationship between the Superaltern, the Subaltern, and the Midaltern

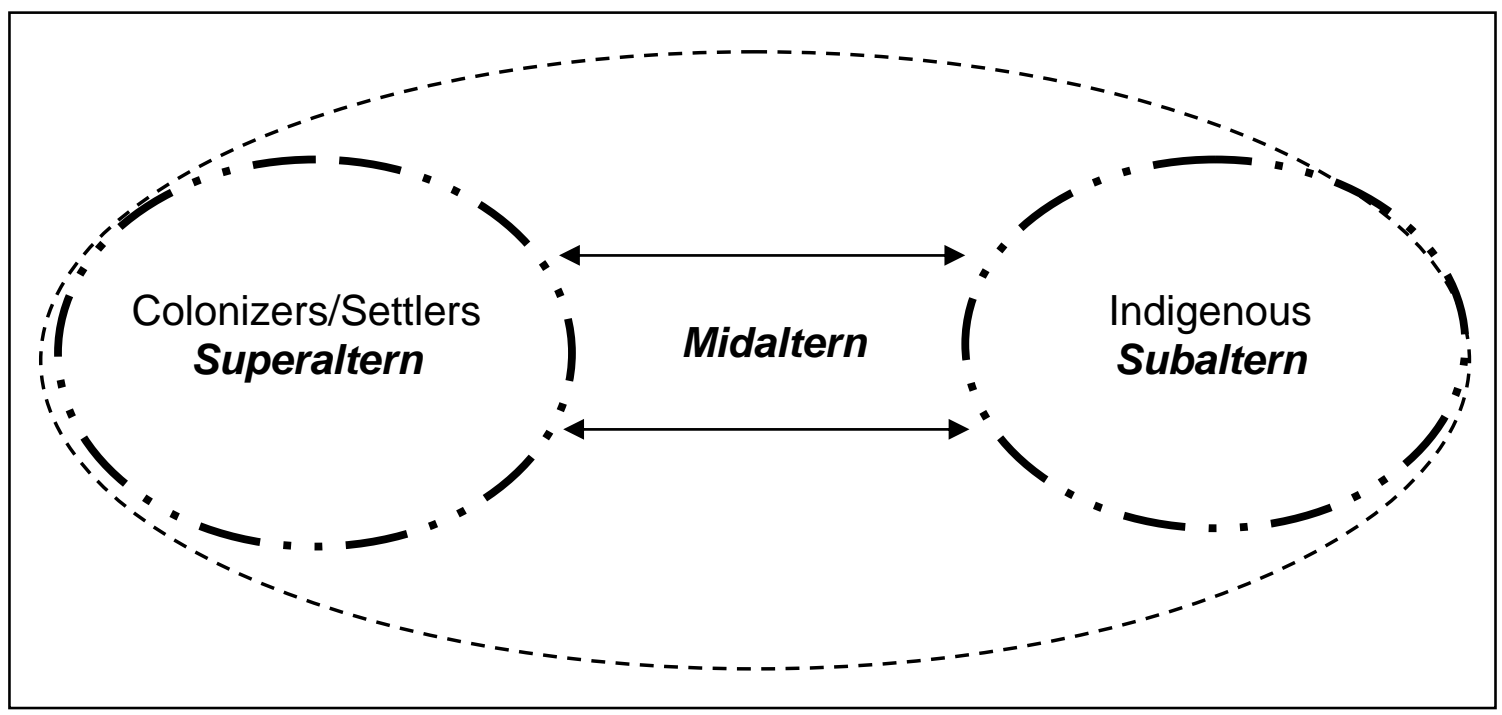

The Relationship between the Particular and the General

While Local multiculture is endemic to Hawai'i and midaltern-type identities are not unique just to the islands, this midaltern discourse offers a means to address some of the most pressing problems facing contemporary societies. Hawai'i's Local midaltern approach may be neither applicable nor directly generalizable to all contexts in the U.S., but this does not rule out the utility of midalternity for transforming the way that Americans consider identity. After all, the dichotomous terms of the current racial discourse in Hawai'i, pitting indigenous peoples against settlers, directly resemble the classic American binary of a color line separating Whites and non-Whites. Many who are engaged in the struggle for social and racial equality, tend in their fervent quest for justice to employ the same kind of limiting discourse that originally helped construct and maintain racial inequality. While this kind of divisive rhetoric may seem effective, in the short term, for bringing grave matters of injustice to the fore, it, in fact, mimics or replicates the same kind of dominant discourse that their struggle seeks to contest (Freire, 1993; Spickard \& Daniel, 2004).

For example, when multiculturalists assert their respective agendas as members of groups who define themselves in monolithic, essentialized, and categorical terms, they, in turn, actually ignore or marginalize those of mixed 
ancestry (Moniz, 2005). Thus, they have replicated the same kind of inequitable power relations that they had sought to challenge (Moniz, 2005). Midalternity offers the promise to end this kind of divisiveness. It does so by providing a more comprehensive metaphor than the color line.

In Hawai'i, the quest for racial justice would not be only for indigenous Hawaiians, but also for all Local multiracial people and settler people who have not shared fully in the rewards of settler colonialism. For example, nonindigenous Locals who feel threatened by the rhetoric of indigenous rights activists would not be as defensive if they did not also feel under attack. In fact, many of these Locals may turn out to be the best allies for indigenous people and their quest for self-determination. When faced with the prospect of the annihilation of cultures, whether they be indigenous, minority, or midaltern cultures, building coalitions instead of alienating potential allies would seem to have a better chance of success in defending those threatened cultures.

A shift towards a more inclusive and thoughtfully nuanced discourse may possibly result in an important realization for non-indigenous Locals who feel threatened by indigenous entitlements and the sovereignty movement. They may finally realize that it is actually in the best interests of all Locals to wholeheartedly support efforts at indigenous self-determination in Hawai'i. As the original inhabitants of Hawai $i$, with a history of experience in the islands stretching back for many centuries, indigenous Hawaiians possess cultural values that are almost certainly the best suited for living in Hawai i. Local culture is heavily interconnected and deeply rooted in this indigenous culture. If protection and active support are not given to indigenous efforts at selfdetermination, there will be a greater chance of the cultures of both indigenous peoples and non-Hawaiian Locals being overwhelmed and trivialized by those whose worldviews emphasize economic exploitation over the preservation of Hawai'i and the protection of its people's rights, responsibilities, and authority over their own lives.

\section{Multicultural Education and Indigenous Education}

Multicultural educators who are already actively engaged and heavily invested in struggles of social justice for indigenous peoples do actually exist. Multicultural education, including the kind of multicultural education closely associated with critical pedagogy, operates under the imperative of achieving educational access, equity, and justice. Those primarily involved in indigenous education who think otherwise may be, understandably, leery. Some so-called multiculturalists, who tout the multicultural education banner, do serve up watered-down or uncritical versions of multicultural education. This is the result of opportunists who take advantage of the growing popularity of the movement and/or unqualified instructors teaching multicultural education courses. But, for the most part, if indigenous educators consider their relationship with the brand of multicultural education described here, they will find a multicultural education 
philosophy anchored in a heavy emphasis on multiple perspectives (See Figure 3). Among those multiple perspectives are certainly indigenous perspectives.

It is important to note that multicultural education affords the possibility to construct and maintain space for indigenous self-determination. Both indigenous and non-indigenous scholars concerned with indigenous self-determination approach the concept of self-determination with healthy skepticism because it is often invoked more rhetorically than pragmatically (McCarty, Borgoiakova, Gilmore, Lomawaima, \& Romero, 2005). The rhetoric of multicultural education provides the potential to privilege indigenous perspectives and to interrogate hegemonic discourses. The following section of this praxis essay focuses on how the theoretical position I outlined actually informs and frames my practice as a multicultural teacher educator in Hawai'i.

Figure 3: Conceptualizing the Relationship between Multicultural Education and Indigenous Education

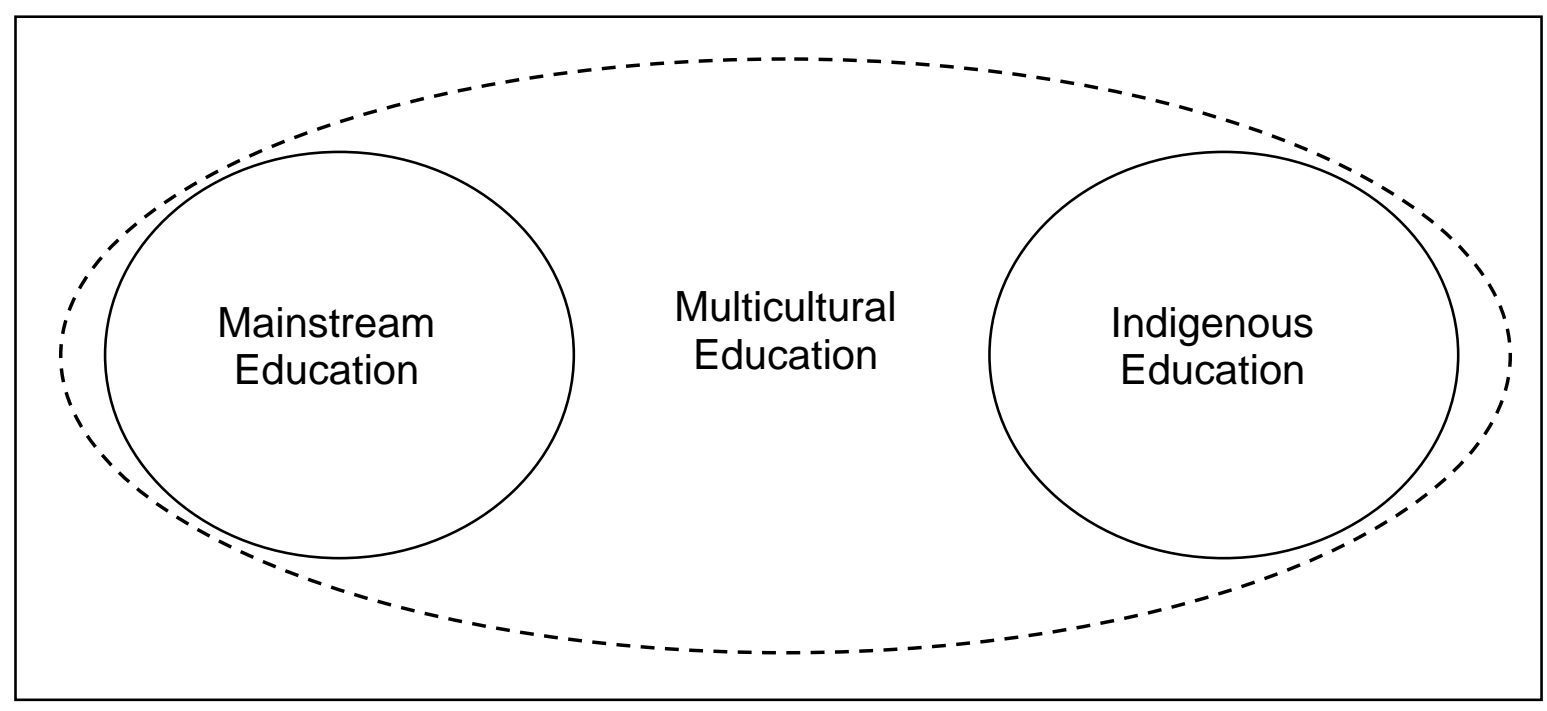

As a multicultural teacher educator positioned in a place where indigenous issues are very salient, I have come to incorporate a number of key points of emphasis that I must address in multicultural education courses - in all of my courses, for that matter. The mere salience of indigenous issues in the Hawai' $i$ context does not absolve me of the duty to explicitly address them in class. Through my experiences of teaching multicultural education courses for five years on the U.S. continent and now for five years back on my home island in Hawai'i, I have developed an idea of some key practices that I must not only include, but also prominently emphasize in my courses. They, briefly, include the following:

1. Build the rationale and openly promote respect for the right for indigenous self-determination. This is a perspective that sometimes is easily dismissed or ignored, so I aim to have my students engage in readings and discussions on this topic. 
2. Interrogate the social hierarchies that exist in Hawai'i. In groups, we tap into students' intuitive knowledge about these hierarchies in the areas of educational attainment, wealth, and social status. Typically, I find that preservice and inservice teachers are very aware of societal inequities that exist. This provides a strong rationale for becoming agents of changing, rather than perpetuating, the current inequitable system.

3. Examine the subjective nature of privilege in Hawai' $i$, based on context. Drawing from and building on Peggy Mclntosh's (1989) classic piece on White privilege, "Unpacking the Invisible Knapsack," I lead my students through various exercises aimed at making visible the invisible, unearned privileges in their everyday lives, particularly in Hawai'i.

4. Construct course assignments that require responses to current issues and events regarding indigenous rights and entitlements. While I do not expect students to adopt a radical pro-indigenous perspective to pass the assignment, or the course for that matter, this practice requires them to engage in thoughtful discussions of indigenous issues.

5. Deconstruct devaluing discourses like "We are a country of immigrants" when they emerge in discussions or in text. Students often repeat the dominant narratives that surround us without critically questioning them. For example, through a careful analysis of the "We are all immigrants." message, students are reminded that there are many in the U.S. whose ancestors did not immigrate into the country. Some were held in bondage and forcibly brought as slaves. Indigenous people already lived in the lands that would become the nation and its holdings. Through this analysis, students realize the virtual erasure of peoples' experiences in our daily, seemingly innocuous, interactions.

\section{Resolution}

Multiculturalism and multicultural education often have a bum rap among those involved in indigenous education in Hawai' $i$. This is understandably so, in light of the superficial multicultural discourse and brands of multiculturalism and multicultural education that have not advanced the cause of indigenous rights.

An organic approach to multicultural education, which actually includes indigenous roots, serves to address the concerns from indigenous education. This approach, based from this locally homegrown multiculture, is characterized by an inclusiveness and fluidity that maintains a space for indigenous selfdetermination, without outside meddling. 


\section{Notes}

1. The term languaculture comes from Michael Agar (1994) who drew from Paul Friedrich's notion of linguaculture. The concept emphasizes the inextricable link between a culture and its language.

2. For the complete definition of multicultural education, as defined by the National Association for Multicultural Education (NAME), see the Resolutions \& Position Papers page on the association's website www.nameorg.org.

3. For a more comprehensive definition of aloha, including its multiple meanings from various sources, especially indigenous Hawaiian language sources, visit the Hawaiian Dictionaries section of Ulukau:The Hawaiian Electronic Library (2004) at www.ulukau.org.

\section{References}

Agar, M. (1994). Language shock: Understanding the culture of conversation. New York: Quill.

Chang, J. (1996). Local knowledge(s): Notes on race relations, panethnicity and history in Hawai'i. Amerasia Journal, 22(2), 1-29.

Delgado, R. \& Stefancic, J. (2001). Critical race theory: An introduction. New York University Press.

DeLima, F. (1991). Frank DeLima's joke book. Honolulu, HI: Bess Press.

Freire, P. (1993). Pedagogy of the oppressed (30 ${ }^{\text {th }}$ Anniversary Edition). New York: Continuum.

Fujikane, C. (2000). Asian settler colonialism in Hawai'i. Amerasia Journal, 25(2), $x x-x x i i$.

Grant, G. (2000). Hawai'i looking back: An illustrated history of the islands. Honolulu, HI: Mutual Publishing.

Grant, G. \& Ogawa, D. M. (1993). Living proof: Is Hawaii the answer? The Annals of the American Academy, 530, 137-154.

Hawai'i Department of Health. (2001). Hawai'i Health Survey 2000: Table 1.1 (Document hhs00t1). Retrieved March 1, 2008, from http://hawaii.gov/ health/statistics/hhs/index.html

Hawai'i Department of Health. (2006). Hawai'i Health Survey 2005: Table 1.1 (Document hhs05t11). Retrieved March 1, 2008, from http://hawaii.gov/ health/statistics/hhs/index.html

Kaomea, J. (2003). Reading erasures and making the familiar strange: Defamiliarizing methods for research in formerly colonized and historically oppressed communities. Educational Researcher, 32(2), 14-25. 
Kaomea, J. (2005). Indigenous studies in the elementary curriculum: A cautionary Hawaiian example. Anthropology and Education Quarterly, 36(1), 24-42.

Lind, A. W. (1938). An island community: Ecological succession in Hawaii. University of Chicago Press.

McCarty, T. L., Borgoiakova, T., Gilmore, P., Lomawaima, K. T., \& Romero, M. E. (2005). Editors' introduction: Indigenous epistemologies and education self-determination, anthropology, and human rights. Anthropology and Education Quarterly, 36(1), 1-7.

McIntosh, P. (1989). White privilege: Unpacking the invisible knapsack. In Peace and freedom, July/August, 10-12.

Moniz, J. (2005). Challenging the hegemony of multiculturalism: The matter of the marginalized multiethnic. In M. Coronado, R.P. Guevarra, Jr., J. Moniz, \& L.F. Szanto (Eds.), Crossing lines: Race and mixed race across the geohistorical divide (pp. 97-116). Lanham, MD: AltaMira Press.

Moniz, J. \& Spickard, P. (2006). Carving out a middle ground: The case of Hawai'i. In D. Brunsma (Ed.), Mixed messages: Multicultural identities in the "color-blind" era (pp. 63-81). London: Lynne Rienner Publishers.

National Association for Multicultural Education (2003). Multicultural Education. Retrieved February 14, 2008, from http://www.namorg.org/papers.html

Okamura, J. Y. (1980). Aloha kanaka me ke aloha 'aina: Local culture and society in Hawaii. Amerasia Journal, 7(2), 119-137.

Okamura, J. Y. (1998). The illusion of paradise: Privileging multiculturalism in Hawai'i. In D. C. Gladney (Ed.), Making majorities: Constituting the nation in Japan, Korea, China, Malaysia, Fiji, Turkey, and the United States (pp. 264-284). Stanford University Press.

Rademaker, J. A. (1947). Race relations in Hawaii, 1946. Social Process in Hawaii, 11. Honolulu, HI: University of Hawai'i Press.

Rosa, J. P. (2000). The Massie Case narrative and the cultural production of Local identity in Hawai'i. Amerasia Journal, 26(2), 93-115.

Spickard, P. \& Daniel, G.R. (2004). Independence possible. In P. Spickard \& G. R. Daniel (Eds.), Racial thinking in America: Uncompleted independence. (pp. 1-17). University of Notre Dame Press.

State of Hawaili Department of Education. (2007). 2006 Superintendent's $17^{\text {th }}$ annual report. Honolulu, HI: Author.

Trask, H-K. (1999). From a native daughter: Colonialism and sovereignty in Hawai'i (Revised edition). Honolulu, HI: University of Hawai'i Press.

Trask, H-K. (2000). Immigrants of color and "immigrant" hegemony: "Locals" in Hawai'i. Amerasia Journal, 26(2), 1-24. 
Trask, H-K. (2002, March 14). We are not happy natives. Public lecture sponsored by the Pacific Islander Student Association and the American Indian Student Association of the University of California, Los Angeles, Kerckhoff Grand Salon. Los Angeles, CA.

Ulukau: The Hawaiian Electronic Library (2004). Hale Kuamo'o Hawaiian Language Center and the Native Hawaiian Library. Retrieved March 1, 2008, from http://www.ulukau.org

United Nations. (2004). The concept of indigenous peoples [Paper prepared by the Secretariat of the Permanent Forum on Indigenous Issues]. (UN Publication PFII/2004/WS.1/3). New York: United Nations Department of Economic and Social Affairs, Division for Social Policy and Development.

United Nations. (2007). United Nations declaration on the rights of indigenous peoples [Resolution adopted by the UN General Assembly on September 13, 2007]. (A/RES/61/295). New York: United Nations Permanent Forum on Indigenous Issues.

U.S. Census Bureau. (2001). Summary file 1: Hawai'i. Retrieved July 25, 2001, from the U.S. Census Bureau Web site: http://www.census.gov

U.S. Census Bureau. (2006). American community survey: Percent of the total population who are two or more races: 2006. Retrieved November 23, 2008, from the U.S. Census Bureau Web site: http://www.census.gov

U.S. Census Bureau. (2007). The American community - American Indians and Alaska Natives: 2004. Retrieved October 28, 2008, from the U.S. Census Bureau Web site: http://www.census.gov

Warner, S.L.N. (1999). Kuleana: The right, responsibility, and authority of indigenous peoples to speak and make decisions for themselves in language and cultural revitalization. Anthropology \& Education Quarterly, 30(1), 68-93.

Yamamoto, E. (1979). The significance of local. Social Process in Hawai i, 27, 101-15. 